\title{
CONSTRUÇÃO DA IDENTIDADE NEGRA NA SALA DE AULA: passando por bruxa negra e de preto fudido a pretinho no poder.
}

\author{
MIZAEL, Náiade Cristina de Oliveira ${ }^{1}$ \\ GONÇALVES, Luciane Ribeiro Dias ${ }^{2}$
}

\section{RESUMO}

Este artigo coloca em debate as questões referentes à educação das relações étnico-raciais e à formação da identidade negra no cotidiano da sala de aula. Busca-se compreender como os (as) alunos (as) negros (as) percebem e vivenciam essas relações de identidade e alteridade e de que maneira é construída (ou não) a identidade negra neste espaço. Trata-se de uma pesquisa qualitativa, realizada em uma escola pública do município de Ituiutaba - MG, numa sala de quinto ano do Ensino Fundamental. Objetivou-se responder a questão: como as crianças negras constroem sua identidade racial na sala de aula? Procurou-se também compreender como os sujeitos da pesquisa se apropriam de conhecimentos sobre e vivenciam as relações étnico-raciais em seu cotidiano. A fim de responder a essas questões, foi utilizada como metodologia a observação participante, acompanhada do diário de campo. As análises se basearam no referencial teórico selecionado, no qual consta, dentre outras fontes, a Teoria das Representações Sociais (TRS). A análise mostrou que a construção da identidade negra positiva no contexto escolar é um processo difícil e contraditório. Entendeu-se que as relações étnico-raciais nesse espaço podem trazer sérias consequências à autoestima dos alunos ao longo de suas vidas. Constatou-se que os estudantes negros convivem diariamente com xingamentos e depreciações em relação à sua pertença identitária. Raros são os momentos em que há exaltação da negritude. Necessita-se que a escola exerça o seu papel formador na perspectiva de planejar, de forma sistêmica, atividades que combatam o racismo em seu interior.

Palavras-chave: Relações étnico-raciais. Identidade negra. Sala de aula.

\footnotetext{
${ }^{1}$ Mestranda em Educação. Bolsista CAPES. Universidade Federal de Uberlândia, FACED/PPGED, Uberlândia - Minas Gerais. E-mail: naiadepetg@gmail.com.

${ }^{2}$ Professora Dra. na Universidade Federal de Uberlândia, Faculdade de Ciências Integradas do Pontal, UFU/FACIP, Ituiutaba, Minas Gerais. E-mail: luciane@pontal.ufu.br.
} 


\begin{abstract}
This article puts in debate the issues related to the education of racial-ethnic relations and the formation of black identity in the everyday classroom. The aim is to understand how students, the black ones, perceive and experience these relations of identity and otherness, and how it is built (or not) the Black identity in this space. It is a qualitative research, held in a public school in Ituiutaba-MG, in a fifth year of elementary school. The objective was answering the question: how the black kids build their racial identity in the classroom? Also, the goal was to try to understand how the subject of the research appropriates knowledge about it and experience the racial-ethnic relations in their daily lives. In order to answer these questions, it was used as a methodology, participant observation, accompanied by the field journal. The analyses were based on theoretical reference selected, in which contained, among other sources, the theory of social representations (TRS). The analysis showed that the construction of black identity in positive school context is a difficult process and adversarial. Understanding the racial-ethnic relations in this space may bring serious consequences to the self-esteem of students throughout their lives. It was noticed that the black students live with daily name-calling and depreciation in relation to their identity belongs. Rare are the times when there is elation of blackness. It is required that the school carries out its role as trainer at prospect of plan, systemic form, and activities to combat racism in itself.
\end{abstract}

Key words: racial-ethnic relations. Black identity. Classroom.

\title{
1 INTRODUÇÃO
}

Pensar a construção da identidade dos sujeitos é algo bastante complexo, pois os seres humanos são submetidos a constantes interações sociais, que os formam no que diz respeito a sentimentos, ações, ideologias, pensamentos etc. Essa cotidianidade, vivida no coletivo e na individualidade, permite que se assumam posturas diante do experienciado nos vários espaços sociais.

Tomamos por base alguns estudos, como o de Cavalleiro (2000) e Fazzi (2006), autoras que adentram a escola para pesquisar as relações étnico-raciais. Seus trabalhos demonstram como as crianças negras, muitas tidas como mulatas, morenas, entre outros termos, vivenciam o preconceito racial por parte dos colegas de maneira extremamente ofensiva. Nesse sentido, Fazzi (2006) argumenta que: 
[...] a socialização entre pares constitui um espaço e tempo privilegiados em que crenças e noções raciais já aprendidas são experimentadas e testadas pelas crianças. E, nessas interações entre si, as crianças vão aprendendo o que significa ser de uma categoria racial ou de outra, criando e recriando o significado social de raça. Observou-se, então, uma espécie de jogo da classificação e autoclassificação raciais, no qual se estabelece um processo de negociação, manipulação e disputa para não ser identificado como um exemplar da categoria preto/negro. Esse jogo se intensifica devido ao reconhecimento da existência de um sistema categorial múltiplo no Brasil. O grande drama desse jogo é a negatividade associada à categoria preto/negro, que expõe as crianças nela classificadas a um permanente ritual de inferiorização, em que são especialmente atingidas por gozações e xingamentos (p. 218).

Assim, o ambiente escolar, local rico para aprendizagens, converte-se em espaço de conflitos e exclusões que são naturalizadas em seu cotidiano pelas práticas sociais (GUIRADO, 1998). Os estudos apresentados nos chamam a atenção para a relevância da temática e impulsionam novos estudos que possam contribuir para uma educação verdadeiramente igualitária, transformadora e que valorize as demais pertenças identitárias.

Escrever sobre identidade não é tarefa simples. Pesquisadores experientes, como Hall (2006), declaram o conceito de identidade como algo complexo, que não é único, mas está em constante processo de mutação. Segundo o autor, existe uma variedade de identidades (gênero, raça, classe social, etnia, nacionalidade, ideologia, profissional etc.). Sendo assim:

A identidade plenamente unificada, completa, segura e coerente é uma fantasia. Ao invés disso, à medida em que (sic) os sistemas de significação e representação cultural se multiplicam, somos confrontados por uma multiplicidade desconcertante e cambiante de identidades possíveis, com cada uma das quais poderíamos nos identificar - ao menos temporariamente (HALL, 2006, p.5).

Sendo assim, na busca pela homogeneização da sociedade, investe-se na construção de uma identidade única, um modelo a ser seguido, tanto na individualidade, quanto nas ações cotidianas nos vários espaços sociais, de lazer, cultura, de aprendizagens formais e não formais. No Brasil, a mestiçagem é a expressão mais popularmente utilizada para demonstrar a busca por uma identidade nacional, racial e cultural singular (MUNANGA, 
1999). No que diz respeito à cultura negra e suas identidades, estas se situam no campo da diáspora e da hibridização, o que significa que na cultura popular negra, em termos etnográficos, não há pureza (HALL, 2003).

A mestiçagem, além de trazer a questão do não puro, ao aproximar-se do ideário de branqueamento pode trazer uma visão de afastamento da identidade negra, que é construída a partir de uma consciência histórica e política. Desta forma:

O mestiço brasileiro simboliza plenamente essa ambiguidade cuja consequência na sua própria definição é fatal, num país onde ele é de início indefinido. Ele é "um e outro", "o mesmo e o diferente", "nem um nem outro", "ser e não ser", "pertencer e não pertencer". Essa indefinição social - evitada na ideologia racial norte-americana e no regime do apartheid -, conjugada com o ideário do branqueamento, dificulta tanto a sua identidade como mestiço, quanto a sua opção de identidade negra (MUNANGA, 1999,p. 126).

Sendo assim, é necessário que se construa a identidade na diferença. E na cultura negra, essas diferenças se revelam na história, através da ancestralidade e de suas tradições, que vão sendo traduzidas, ressignificadas. A identidade negra se constrói na resistência do povo negro contra toda e qualquer forma de discriminação racial, que acaba por criar produtos culturais, como a música, o rap (ritmo e poesia), o qual vai se modificando e cantando o novo contexto, consciente desse pertencimento racial.

Essa consciência vem à tona através de relações e ações políticas que promovem o conhecimento e a valorização dessa identidade. É preciso vencer a segregação racial que favorece a cultura branca em detrimento da negra e, consequentemente, revela o racismo, muitas vezes de maneira velada.

\section{METODOLOGIA}

O presente artigo resulta de uma pesquisa qualitativa, realizada em uma escola estadual do município de Ituiutaba - MG, em uma sala de quinto ano do ensino fundamental, no período de três meses. Os estudos apresentados nos chamam a atenção para a relevância da 
temática e impulsionam novos estudos que possam contribuir para uma educação verdadeiramente igualitária, transformadora e que valorize as demais pertenças identitárias.

Entre o referencial teórico utilizado para a análise dos dados, consta a Teoria das Representações Sociais (TRS), sobre a qual Arruda (2002) discorre embasado em Serge Moscovici, autor que teoriza a representação social sob a perspectiva psicossocial:

A psicologia social aborda as representações sociais no âmbito do seu campo, do seu objeto de estudo - a relação indivíduo-sociedade - e de um interesse pela cognição, embora não situado no paradigma clássico da psicologia: ela reflete sobre como os indivíduos, os grupos, os sujeitos sociais, constroem seu conhecimento a partir da sua inscrição social, cultural etc., por um lado, e por outro, como a sociedade se dá a conhecer e constrói esse conhecimento com os indivíduos. Em suma, como interagem sujeitos e sociedade para construir a realidade, como terminam por construí-la numa estreita parceria - que, sem dúvida, passa pela comunicação (ARRUDA, 2002, p. 128).

Sendo assim, busca-se, através da Teoria das Representações Sociais, compreender como os sujeitos constroem conhecimentos sobre determinadas realidades em seu cotidiano; como os alunos negros vivenciam junto aos alunos brancos as relações raciais na rotina da sala de aula, em uma dinâmica constante de produção de saberes.

Também foi utilizada a observação participante, eficaz na medida em que coloca o pesquisador no campo de pesquisa para observar, permitindo que este participe de alguns momentos da rotina do grupo em observação. Com isso, o registro das atividades ocorridas em campo ou mesmo as percepções do pesquisador se tornam elementos relevantes para o processo de estudo.

\footnotetext{
A observação participante ativa ocorre em consonância com o percurso da investigação, tendo como foco a comunidade, a escola e as experiências em aulas, colocando como instrumento de registro o diário de campo do pesquisador, que após cada dia de observação fará uma leitura cuidadosa com o intuito de estabelecer escolhas e direcionamentos das narrativas e de outros dados, de acordo com os objetivos e questões da pesquisa (LIMA; PEREIRA, 2010, p. 10).
}

Deste modo, a valorização da observação participante, tendo como suporte o diário de campo, é que permitirá ao pesquisador o relato das situações que ele se propôs a investigar, organizando as ideias para uma análise que objetive responder à problemática da 
pesquisa. A observação participante, enquanto recurso metodológico, possibilita a inserção no campo a ser estudado, de maneira a conhecê-lo, com seus sujeitos e suas relações, o que contribuirá para a produção de conhecimentos críticos e transcendentes ao senso comum, os quais a TRS explica bem.

Além da já citada Teoria das Representações Sociais, este estudo se sustentará em Hall (2003; 2006), buscando compreender a formação da identidade; nas contribuições de Heller (1992) sobre o cotidiano, na intenção de abordar o cotidiano escolar; e em Munanga (1999), que trata da identidade negra.

As observações em campo duraram três meses e se deram no quinto ano do ensino fundamental, em uma sala de 18 alunos, na qual identifiquei oito alunos negros, pelo tom de pele, mas ideologicamente considerados mulatos, pardos e morenos escuros (MUNANGA, 1999). Posteriormente, consideramos duas crianças em particular, destacadas pelas situações que iam vivenciando.

\section{CONHECENDO O CAMPO PESQUISADO}

No início das observações, supunha-se que as relações raciais estariam amenizadas e menos conflituosas. Isso se deu por que não percebemos de imediato as situações de discriminação racial ou por acreditarmos ingenuamente que esta teria sido superada em sua forma explícita, pelo menos de forma parcial. No entanto, os dados coletados vão ao encontro de outros estudos que têm denunciado o racismo no cotidiano escolar ao longo de várias décadas, assim como as já mencionadas contribuições de Cavalleiro (2000) e Fazzi (2006).

Logo registramos várias situações, como tons de fala pejorativos em relação ao negro, no sentido de sua inferiorização explícita. As cenas de discriminação cotidiana são reais. O que é invisibilizado é o tratamento pedagógico que a escola, no caso, o professor poderia dar para modificar essa realidade.

As falas registradas neste trabalho deram-se de forma espontânea, em meio às atividades dos alunos em sala de aula, quando copiavam tarefas e conversavam, salvo uma conversação que ocorreu na quadra poliesportiva. No período da participação no campo, não 
havia momentos ou planejamentos dirigidos para discussões sobre as questões raciais no plano pedagógico.

Trazemos neste trabalho situações de discriminação racial vivenciadas por duas crianças negras. $\mathrm{O}$ texto se foca nestas pelo fato de serem as que vivenciaram os momentos a serem elucidados posteriormente. Tratam-se também das crianças negras mais atuantes na sala de aula, no sentido de possuírem características que as colocavam em posição de centralidade, chamando assim mais atenção nesse espaço.

A primeira aluna negra, Alice ${ }^{3}$, é considerada "garota problema"; tem comportamento rebelde dentro da sala, chegando a insultar a professora. Muitas vezes é levada à força, puxada pelo braço, para fora de sala e chora. A professora diz que ela é dissimulada, que seu humor muda de acordo com suas vontades.

Percebe-se que não faz as tarefas e está sempre fora da sala. É um pouco agressiva com os colegas (meninos), que zombam dela, principalmente no que se refere ao padrão de beleza. Percebe-se que também quer chamar a atenção, haja vista que a turma está num período de paquera, na transição da infância para a pré-adolescência. Em meio a esse contexto, como uma garota que quer ser admirada se vê? Em atividades desenvolvidas em roda, os meninos se esquivam dela, não querem pegar em sua mão; ela finge não ligar e também se esquiva, como autodefesa. É também carinhosa e gosta de colocar suas opiniões em sala, mesmo que muitas vezes se coloque em meio a conflitos ou acabe causando-os.

O segundo aluno negro, Rafael, é o oposto de Alice em se tratando de como é percebido em sala. Demonstra interesse pelas atividades propostas, preocupa-se com suas notas escolares, é carinhoso e considerado por sua beleza. Causa simpatia nas pessoas ao redor: estagiários, colegas e professores, o que não o impede de vivenciar momentos tensos de racismo.

Ambas são crianças com atuações fortes na sala de aula observada e já trazem consigo uma bagagem de vivências que marcam seu processo de construção de identidade.

Dentre as situações de preconceito racial apreendidas no cotidiano escolar, categorizamo-as em: 3.1) padrão de beleza e identidade negra; 3.2) aspecto inferiorizante

\footnotetext{
${ }^{3}$ Uso de nome fictício. Dá-se para a preservação da identidade das crianças.
} 
relacionado ao ser negro; 3.3) aspecto exaltante da identidade negra e contradições. Detalharemos estes tópicos a seguir.

\subsection{Padrão de beleza e identidade negra}

Quantos nãos me disseram, nego imagine?

Mas determinação e raça é o que me define

Do meu sonho vários lobos sempre deram risadas

Só que eu nunca me vi assim como uma piada

Riam do nariz, das letras e da roupa

Riam do cabelo, da cor e da minha boca

Exatamente tudo aquilo que deixa as minas louca

Só que minha missão nesse mundo é outra (LUO, 2010).

Nessa música o rapper faz menção à sua trajetória de vida desde a infância, narrando os desafios enfrentados por ser negro e pobre. O trecho enuncia seu sonho pela carreira musical e as dificuldades de ascensão social tendo em vista sua pertença identitária. Demonstra também como a estética negra é considerada inferior e motivo de piadas racistas, o que influencia nesse processo de construção da identidade e na batalha solitária para seguir em frente.

Concomitante a isso, no cotidiano escolar pesquisado nota-se a influência do padrão de beleza europeu na formação da identidade negra e o reflexo dessa influência nas demais crianças:

Uma aluna chama a atenção: Alice. Observo que não gosta de ficar dentro da sala, assim como outros alunos. No entanto, ela sai o tempo todo. A professora até se acostumou, assim como a diretora. Vejo da janela que muitas vezes ela auxilia a professora de Educação Física, conduzindo as alunas menores para o bebedouro ou fazendo brincadeiras com estas. No primeiro dia que cheguei, já foi me dizendo quem eram as duas meninas consideradas as mais bonitas da sala (DIÁRIO, 2013).

Ao longo da pesquisa, percebemos que as meninas citadas por Alice são consideradas as mais bonitas também pelos meninos da sala. Uma delas é branca, de olhos claros e cabelos lisos; a outra, com estética aproximada ao padrão branco, tem cabelos mais lisos. Vale destacar que a beleza dessas meninas é afirmada inclusive pelos meninos tidos como os mais 
bonitos da sala, os quais também apresentam estética aproximada ao padrão europeu. Isso nos diz do porque de Alice acreditar em tal constatação, já que percebe essas representações do que é mais bonito a partir de seus colegas de sala. Gomes (2002), ao tratar do padrão de beleza europeu, explica que:

Foi a comparação dos sinais do corpo negro (como o nariz, a boca, a cor da pele e o tipo de cabelo) com os do branco europeu e colonizador que, naquele contexto, serviu de argumento para a formulação de um padrão de beleza e de fealdade que nos persegue até os dias atuais (p.42).

Alice, então, responde a essa realidade segundo um padrão eurocêntrico, que ela vive e que a faz acreditar que o "belo" é o branco ou o que se aproxima deste, em nível de superioridade. Deste modo, assumir uma identidade negra em meio a um contexto que a todo o momento tenta anulá-la não é tarefa fácil.

Tais consequências de uma história distorcida, que traz um padrão de beleza único, necessitam de uma ação política para a desconstrução destes estereótipos, defendendo assim a diversidade cultural em toda sua amplitude. Silva (2000) explica que há uma relação de poder na tentativa de se normalizar uma determinada identidade como sendo $a$ identidade: "Normalizar significa atribuir a essa identidade todas as características positivas possíveis, em relação às quais as outras identidades só podem ser avaliadas de forma negativa" (p.83).

Por isso, a construção de um olhar mais alargado para os valores e as representações com que crianças e jovens negros são confrontados em sala de aula durante a formação de sua identidade é de suma relevância social e pedagógica.

\subsection{Aspecto inferiorizante relacionado ao ser negro}

Atrasado eu tô um pouco sim, tô eu acho

Só que tem que seu jogo é sujo e eu não me encaixo,

Eu sou problema de montão, de carnaval a carnaval

Eu vim da selva, sou leão

Sou demais pro seu quintal

Problema com escola eu tenho mil, mil fita[...] (BROWN; ROCK; 2002). 
O trecho acima trata da questão do ser negro em um contexto permeado pela discriminação racial, fazendo alusão ao seu consequente atraso social. Eis o jogo sujo a que se refere: uma história que é marcada pelo branco impondo ao negro a condição de inferior. $\mathrm{O}$ rapper faz menção à escola enquanto espaço problemático, de tensões raciais excludentes. Assim como vários produtos culturais dos movimentos negros, o rap expressa uma ação de valorização do ser negro, incentivando esses sujeitos a não se adequarem ou se subordinarem ao sistema racista.

É preciso resgatar, mesmo que de forma panorâmica, a luta que vem sendo empreendida, ao longo da história do Brasil, pela população negra pela liberdade, pela família, pela dignidade no trato, por educação, por salários dignos etc., considerando, historicamente, essa ordem nas reinvindicações. Torna-se fundamental para que se estabeleça outra imagem sobre o negro que não a paradoxal representação, do ora pacífico/ submisso ou brutalizado/ agressivo (GARCIA, 2007, p. 28).

O campo pesquisado diz de uma violência racial contínua, em que os negros (as) são vistos (as) como menores em relação aos brancos (as), são desrespeitados (as) em sua integridade moral e física, o que consequentemente interfere de forma negativa na construção de sua identidade negra, bem como no desenvolvimento pleno desses sujeitos. Esse processo racista cruel perpetua-se ao longo da história desde a colonização, tanto implícita quanto explicitamente, como demonstrado nas situações vivenciadas durante da pesquisa.

Em meio à aula, os meninos sempre zombando, falando que Alice é feia, chegaram a chamá-la de bruxa negra (momento este que acontece durante a cópia de tarefas). Nestes momentos, Alice revida com xingamentos, o que acaba por causar tumulto muitas vezes. Os colegas riem e a professora nem percebe ou finge não ver. Sendo assim, o conflito se encerra sem intervenções, como se fosse um momento de conversa informal entre alunos, que dissesse respeito somente a estes. (DIÁRIO, 2013).

Embora se tratasse de um momento de estudo formal em sala de aula, em que a temática era abordada pelos próprios alunos, a situação de discriminação seguiu invisibilizada pela professora. No que se refere aos sujeitos e às situações que permeiam suas relações, sob a compreensão da Teoria das Representações Sociais: “A realidade é socialmente construída e o 
saber é uma construção do sujeito, mas não desligada da sua inscrição social" (ARRUDA, 2002, p.131).

Os momentos de diálogo entre os alunos são explicados pela teoria citada acima enquanto oportunidades de produção de saberes em determinados espaços sociais, no caso a sala de aula, e que dizem de uma visão de mundo, mesmo que do senso comum, representada por emoções e vivências em sociedade; o que demonstra a potencialidade dos acontecimentos em sala de aula para a desmistificação de preconceitos, aspecto que poderia ser trabalhado pedagogicamente.

O termo utilizado, "bruxa negra", adjetivação pejorativa, contribui para a afirmação e reprodução depreciativa da imagem negra, colocando-a enquanto algo considerado feio e negativo. Outro momento da pesquisa de campo merece destaque, o único ocorrido fora da sala de aula, na quadra de esportes, horário em que fazemos atividades pedagógicas e movimento:

No meio das atividades, o mesmo aluno negro, Rafael, com quem eu tinha conversado anteriormente sobre as questões étnico-raciais, estava conversando com outro colega quando ouvi este gritar: Ah, seu preto fudido! Virei-me e perguntei o que ele tinha dito e ele, sem graça, me disse: "Ele é meu amigo". Aí outro colega que estava por perto disse: "Ele disse 'seu preto fudido', tia". Eu disse que ele não deveria dizer isso, que tanto o preto quanto o branco tinham valor. $\mathrm{O}$ menino se mostra sem graça e continua sua atividade (DIÁRIO, 2013).

Nesse momento, percebemos que Rafael fica sem reação, parece até envergonhado, sem saber como enfrentar a situação, o que demonstra o peso de tais palavras, as quais atribuem dado valor à sua condição de negro. Compreende-se a falta de resposta de Rafael, até por que o aluno branco se esquiva do peso de sua ação ao relativizá-la, afirmando que Rafael é seu amigo, portanto, o caso poderia passar por um "desentendimento" momentâneo.

Fazzi (2006, p. 213) ao pesquisar sobre como as crianças vão elaborando suas próprias experiências raciais, esclarece que: "[...] o discurso relativizador e o preconceito racial são componentes do processo de socialização das crianças, e ambos estão em processo 
de cristalização e de estabilização durante a infância". Contudo, isso não impede a ação preconceituosa.

Ou seja, a criança sabe que sua atitude está errada, mas já vai apreendendo maneiras de mascarar o preconceito racial, culminando no discurso de igualdade, tão proclamado e instaurado em legislação, mas que na prática não se sustenta, pois vivemos em uma sociedade cotidianamente racista em suas relações e consequentes representações. É o que notamos durante a observação participante:

Nesse dia o mesmo aluno que chamou o colega negro de "preto fudido" começa a zombar de Alice, em meio à aula, cantando: "nega do subaco cabeludo, vem ni mim [...]". Chamo sua atenção e ele me diz que é uma música e se vira para copiar sua tarefa (DIÁRIO, 2013).

Essa situação é permeada pelo preconceito para com o negro, associando sua imagem à sujeira, ao desmazelo; e novamente encontra-se o discurso relativizador para justificar tal ação. O caso revela como a criança branca percebe as influências midiáticas e se apropria delas, reproduzindo a discriminação racial. Os três episódios permeados por adjetivação pejorativa em relação à pertença racial revelam valores e concepções sobre a identidade afro-diaspórica com que esses alunos negros são confrontados cotidianamente no ambiente escolar.

Ao longo de dois dias seguidos que estamos na sala, Alice discute com a professora, fala alto com ela, sai da sala, é mandada para a diretoria, muitas vezes saindo da sala para passear com outra colega. Uma das alunas, considerada entre as mais bonitas da sala, me diz que Alice é suspeita de ter roubado dinheiro da professora. Segundo ela, no dia seguinte a professora relata que o dinheiro sumiu e que o mesmo era para comprar leite para sua neta. O fato não foi esclarecido, mas a suspeita se sustenta pelo comportamento de Alice (DIÁRIO, 2013).

A situação acima nos permite analisar que o padrão estético transfere-se para padrões éticos, agregando ideia de valor, o que vai acumulando referências negativas à identidade negra. Percebe-se aqui a confirmação de um dado cruel, em que se perpetua ao longo da história os estereótipos em relação ao negro forjados no período colonial: ele continua a ser visto com desconfiança, como alguém que poderia desenvolver atitudes 
suspeitas, com hábitos de libertinagem, não passível de capacidade intelectual etc. No entanto, essas manifestações se modificam nos discursos racistas, travestidos de meras opiniões, ao que Silva (2000) explica bem:

Quando utilizo a expressão "negrão" para me referir a um homem negro, não estou simplesmente manifestando uma opinião que tem origem plena e exclusiva em minha intenção, em minha consciência ou minha mente. Ela não é a simples expressão singular e única de minha soberana e livre opinião. Em um certo sentido, estou efetuando uma operação de "recorte e colagem". Recorte: retiro a expressão do contexto social mais amplo em que ela foi tantas vezes enunciada. Colagem: insiro-a no novo contexto, no contexto em que ela reaparece sob o disfarce de minha exclusiva opinião [...] (p.95).

Sendo assim, o estereótipo, enquanto generalização do ser negro sob uma visão preconceituosa que prevê uma negatividade, acaba por perpetuar o sistema colonizador, o que deve ser combatido pela escola, na sala de aula, entendendo-a como espaço transformador, de desmistificação desses saberes alienantes e discriminatórios.

\subsection{Aspecto exaltante da identidade negra e contradições}

Muito amor, muito amor, pelo som, pela cor

A herança tá no sangue, louvado seja o meu senhor.

Que me quis, descendente de raiz.

Preto, função, sou sim, sou feliz.

Favelado legítimo, escravo do ritmo.

Dos becos e vielas eu sou amigo íntimo.

Dexter o filho da música negra

Exilado sim, preso não, com certeza

O rap me ensinou a ser quem eu sou

E honrar minha raça pelo preço que for

Dos vida loka da história eu sou um a mais

Que te faz ver a paz como um soro eficaz (DEXTER; BROWN; FUNÇÃO, 2006).

Neste trecho, assim como ao longo da música, o enunciador poetiza seu orgulho em ser preto e poder cantar a música negra, haja vista que esta se torna ferramenta política para a valorização de sua história, denunciando e questionando as desigualdades 
raciais. O rapper, assim como outros citados ao longo do trabalho, demonstra a reconstrução positiva de sua identidade negra, em que o fator preponderante é o rap.

Outro aspecto desvendado nas falas das crianças durante o período de observação trata-se de como percebem a si mesmos e sua condição racial. De certa forma este aspecto revelou-se antagônico. Por vezes as crianças demonstravam total desprezo à pertença étnico-racial negra. Em outros momentos, externavam orgulho em relação a isso.

Algumas formas de tratamento traziam aspectos positivos e se apresentavam como uma forma de empoderamento e identificação. Por exemplo, a expressão "Pretinho do poder", com a qual Rafael se denominava e seus colegas achavam legal, chamando-o assim também, relaciona a imagem negra com a identidade positiva midiática do cantor Thiaguinho ${ }^{4}$. Em outros momentos, os alunos diziam: “Ah, o Charles ${ }^{5}$ dança bem, pois faz parte do Congo", demonstrando o valor cultural e um aspecto positivo da cultura do congado.

Tais fatores indicam também os contrastes e nuances que o cotidiano desses alunos negros traz como representação do ser negro (a). Em meio aos estereótipos, as representações positivas também são buscadas por esses sujeitos como forma de se colocarem no mundo de maneira positiva e bela.

Em meio à aula, um aluno me pergunta se conheço uma estagiária que vai à escola na parte da manhã, morena, com 'pernonas'. Pergunto se ela é negra (o aluno é negro), ele diz que sim, diz que é igual à Alice. Alice não gosta quando ele diz isso e digo que ser negra é bonito, assim como eu, e ela grita: "Você é parda!". Depois ouço o aluno negro falando para os colegas que é mulato, pois sua mãe é branca e seu pai negro. Eles sempre dialogam durante a cópia de tarefas do quadro (DIÁRIO, 2013).

Neste trecho Rafael tenta dizer que acha a estagiária bonita, apesar de esta ser negra. Ao responder que as negras também são bonitas, me referindo a mim por saber que me viam de maneira positiva, Alice não concorda, rejeitando assim a cor preta. Para ela, estava bem que eu não fosse branca, mas também não me considerava negra. Logo Rafael utiliza o

\footnotetext{
${ }^{4}$ Cantor de pagode, compositor e instrumentista.

${ }^{5}$ Charles é um menino negro que participa de uma confraternização na sala observada no momento elucidado.
} 
termo mulato, igualmente fugindo da condição de negro e já assimilando que na proximidade da cor branca haveria uma maior "aceitação" e valorização.

Ser escuro é ser menos e ser claro é ser mais, portanto, há um princípio de valor cultural e, nesse sentido, os escuros são negros e os claros são brancos. Os escuros vieram da África e os brancos da Europa. [...] Mas, ao construirse esse contínuo gradual de cores, constrói-se ao mesmo tempo, a oposição de brilho e ausência de brilho, ou seja, no limite os claros são brancos e os escuros são pretos, valorizam-se ou hierarquizam-se os tons, e os claros são melhores. (MAGGIE, 1991, p. 81 apud MUNANGA, 1999, p. 119).

Deste modo, cai-se na ideologia do branqueamento, na qual a mestiçagem seria fator preponderante para uma identidade nacional, para acabar com o elemento negro, numa política racista que nada tem a ver com democracia racial.

A política e ideologia do branqueamento exerceram uma pressão muito forte sobre os africanos e seus descendentes. Foram, pela coação, forçados a alienar sua identidade, transformando-se, cultural e fisicamente em brancos (MUNANGA, 1999, p.94).

Tal política encontra-se enraizada nos brasileiros, mestiços, morenos, pardos, mulatos que, defrontados com o racismo cotidiano a si e a seus ancestrais, são impedidos muitas vezes de galgar determinados espaços sociais. Esses negros, muitas vezes sem uma formação política de qualidade, acabam por interiorizar o discurso da classe dominante elitista e racista, segundo o qual somos uma nação de identidade única, embora miscigenada, cujos habitantes são vistos enquanto iguais.

Se a intenção é proclamar uma identidade nacional única, por que se assiste a uma valorização excessiva, pelos canais de comunicação e instituições, da cultura européia? Brancos que louvam a sua condição de brasileiros, porém, mais do que isso, exaltam suas descendências italiana, espanhola, portuguesa? Estas são supervalorizados, às custas do silêncio sobre a história e cultura africana e afro-brasileira. É aí que se encontra a problemática: a identidade nacional é tão falsa como a miscigenação enquanto ideologia.

Percebe-se, assim, a intenção de anular o negro na história do Brasil, com a postura de colocar o mestiço em um "lugar nenhum", sem história e, portanto, sem identidade 
étnica, desarticulando assim o movimento negro e sua luta pela valorização da identidade negra (MUNANGA, 1999).

Deste modo, entende-se a identidade negra enquanto uma construção coletiva de pardos, mulatos e negros que, conhecedores de sua história, não somente dos sofrimentos aos quais foram submetidos seus ancestrais quando escravizados, mas também das lutas por liberdade, igualdade e dignidade, reconhecendo o negro como um povo que ajudou a construir este país, não apenas através mão de obra, mas também por meio do saber intelectual.

O que a Lei 10.639/03, sob o apoio das Diretrizes Curriculares Nacionais para a Educação das Relações Ético-Raciais e para o Ensino de História e Cultura Afro-Brasileira e Africana, vem legitimar é a promoção de ações que visem a igualdade racial no seio escolar e acadêmico e que possam, posteriormente, atingir outros espaços sociais.

Entende-se que esse processo de discriminação racial vivida cotidianamente pelos alunos negros na sala de aula influencia e impede diretamente a construção de uma identidade racial positiva, haja vista que: "a infância é um momento importante, pois, as crianças estabelecem relações com as outras pessoas e começam a formar a sua auto-estima a partir do tratamento recebido nessas relações" (FRANCO, 2012, p.13).

Sendo assim, se essas crianças são olhadas, faladas e representadas por estereótipos negativos em função de serem negras, - pois não há dúvida quanto a isso: mesmo que algumas se considerem mestiças ou pardas, elas são reconhecidas imediatamente pelos alunos brancos como negras-, torna-se difícil e complexa a formação dessas crianças no que diz respeito à consciência racial.

O transitar desses alunos por termos que fogem à raça negra demonstra essa dificuldade de uma identificação sólida. Ao mesmo tempo, buscam com orgulho referências positivas de ser negro, evidenciando assim o processo de construção identitária em que se encontram, marcado pelo difícil dilema entre a negação constante do seu pertencimento racial e a afirmação do mesmo.

O olhar para essas relações raciais na sala de aula permite vislumbrar como o racismo faz parte da vida cotidiana desses alunos e como estes assimilam e experienciam tais atitudes. É evidente também a naturalidade com que são discutidas as questões raciais pelos 
alunos no ambiente escolar, o que poderia ser potencializado para direcionar o debate numa perspectiva transformadora das relações raciais.

Essas observações e discussões sobre como os alunos constroem as representações sociais em torno do ser negro, poderiam ser exploradas em favor da (re) construção de uma identidade negra positiva, já que esta, em se tratando do presente estudo, se mostrou deturpada pela visão distorcida da história e consequentemente da identidade afro-brasileira.

A partir do conhecimento de sua história, o negro pode sair do campo indefinido, pardo, e assumir sua identidade negra. Esta não precisa nem pode ser imutável, mas que tenha significado político. Que os alunos negros possam enfim dizer de si, saindo do lugar da inferioridade para a potencialidade do ser negro, sabendo enfrentar qualquer atitude discriminatória a partir de uma autoestima elevada e confiante.

\title{
4 CONSIDERAÇÕES FINAIS
}

\author{
O sistema é racista, cruel \\ Levam cada vez mais \\ Irmãos aos bancos dos réus \\ Os sociólogos preferem ser imparciais \\ E dizem ser financeiro o nosso dilema \\ Mas, se analisarmos bem mais você descobre \\ Que negro e branco pobre se parecem \\ Mas não são iguais \\ Crianças vão nascendo \\ Em condições bem precárias \\ Se desenvolvendo sem a paz necessária \\ São filhos de pais sofridos \\ E por esse mesmo motivo \\ Nível de informação é um tanto reduzido (BROWN, 1990).
}

A população negra, que é mais da metade da sociedade brasileira, sofre racismo todos os dias, o que se dá de maneira cruel, pois este é invisibilizado e relativizado em sua manifestação cotidiana, num discurso falso de igualdade social. Trata-se, assim, de uma ação sistematicamente política, que visa continuar relegando os negros aos papéis mais baixos da sociedade, sem educação, saúde, moradia, lazer, enfim, sem o básico para garantir uma vida de qualidade. 
Esse cotidiano faz parte da escola. A sala de aula pesquisada reflete um espaço de tensões raciais evidentes, onde os alunos estão diariamente construindo entre si visões sobre as questões étnico-raciais. No entanto, o que poderia ser dado era o trato pedagógico a esses conhecimentos que fazem parte e dizem de uma sociedade, pois, mesmo invisibilizados, esses saberes permeiam todos os espaços.

Percebe-se que no ambiente estudado existe um antagonismo entre uma imagem pejorativa do negro ("bruxa negra" e "preto fudido") e uma exaltação da negritude ("pretinho no poder”). Embora a primeira postura prevaleça, a segunda revela a busca desses atores negros por se identificarem e serem vistos como algo bom, digno.

A construção da identidade negra positiva em meio a esse cotidiano da sala de aula se torna um processo complexo e até mesmo solitário, no qual os alunos negros buscam representações que resistam à imagem estereotipada e preconceituosa que lhes é atribuída. Representações estas que não são exploradas pela professora, por isso da solidão do indivíduo. No entanto, também existem vários movimentos negros que procuram colocar em destaque sua cultura, sua estética e história, de maneira a resistir a essa discriminação racial.

Gravíssimo é pensar que a construção dessa identidade negra pode não acontecer, de modo que o aluno (a) negro (a) vislumbra dois caminhos: ou se anula para ser aquilo que não é, aceitando o papel de inferior, ou terá a possibilidade de, em dado momento, reconstruir essa identidade a fim de se libertar de todos os preconceitos com relação a si mesmo para então ser capaz de se posicionar politicamente enquanto negro (a).

Sendo assim, é de extrema urgência o desenvolvimento de atividades pedagógicas intencionais que tratem das relações raciais no sentido de desconstruir os estereótipos e a discriminação racial. Para isso, além de uma formação docente na perspectiva das relações raciais, faz-se necessário a produção/utilização de material didático que aborde a temática numa perspectiva descolonizante e antirracista. 


\section{REFERÊNCIAS}

ARRUDA, Ângela. Teoria das representações sociais e teorias de gênero. Cadernos de Pesquisa, n. 117, p. 127-147, nov. 2002. Disponível em:

$<$ http://www.scielo.br/pdf/cp/n117/15555.pdf> Acesso em: 20. nov. 2013.

APPOLINÁRIO, Fabio. Metodologia da ciência: filosofia e prática da pesquisa. São Paulo: Thomson Pioneira, 2006.

BRASIL. Ministério da Educação. Diretrizes Curriculares Nacionais para a Educação das Relações Étnico-Raciais e para o Ensino de História e Cultura Afro-Brasileira e Africana. Brasília, DF, 2004. Disponível em : < http://www.acaoeducativa.org.br/fdh/wpcontent/uploads/2012/10/DCN-s-Educacao-das-Relacoes-Etnico-Raciais.pdf $>$. Acesso em: 14 fev. 2014.

Lei 10.639/03: Inclui no currículo oficial da rede de ensino a obrigatoriedade da temática história e cultura afro-brasileira. Brasília, DF, 2003.

BROWN, Mano. Intérprete: Racionais Mc's. Racistas otários. In: BROWN, Mano. Holocausto Urbano. [S.1]: Zimbabwe, 1990. 1 disco sonoro. Faixa 5. 2014.

; DEXTER, Marcos; FUNÇÃO, Di. Intérprete: Dexter; Mano Brown; Função. Eu sou função. In: BROWN Mano; DEXTER; FUNÇÃO. Exilado sim, preso não! [S.l: S.n.], 2006. 1 disco sonoro. Faixa 10.

; ROCK Edi. Intérprete: Racionais Mc's. Negro drama. In: BROWN Mano; ROCK Edi. Nada como um dia após o outro dia. [S.1]: Cosa Nostra, 2002. 1 disco sonoro. Faixa 5.

CAVALLEIRO, Eliane. D. S. Do silêncio do lar ao silêncio escolar: racismo, preconceito e discriminação na educação infantil. São Paulo: Contexto, 2000. 110 p.

CORSI, Adriana Maria; LIMA, Emília F. de. Práticas Pedagógicas no ensino fundamental na perspectiva do multiculturalismo crítico. Currículos sem fronteiras, São Carlos, v.10, n.2, p.158-182, Jul/Dez 2010.

DIÁRIO de campo. Ituiutaba. [s.n], 2013.

FAZZI, Rita de Cássia. O drama racial de crianças brasileiras: socialização entre pares e preconceito. Belo Horizonte: Autêntica, 2006.

FRANCO, Nanci Helena. R. Imagens no espelho: percepção de adolescentes negros sobre o seu pertencimento étnico-racial. In: COLÓQUIO INTERNACIONAL EDUCAÇÃO E CONTEMPORANEIDADE, 6., 2012. São Cristóvão, SE. Anais... São Cristóvão, SE, [S.n.], 2012, p. 1-15. 
GARCIA, Renísia Cristina. G. Identidade fragmentada: um estudo sobre a história do negro na educação brasileira: 1993 - 2005. Brasília: INEP, 2007.

GUIRADO, Marlene. Diferença e alteridade: dos equívocos inevitáveis. In: Diferenças e preconceito na escola: alternativas teóricas e práticas. São Paulo: Summus, 1998.

GOMES, Nilma L. Educação, raça e gênero: relações imersas na alteridade. Cadernos Pagu. São. Paulo, n. 6-7, p. 67-82, abril 1996.

. Trajetórias escolares, corpo negro e cabelo crespo: reprodução de estereótipos ou ressignificação cultural? Revista Brasileira de Educação, [s.1], n. 21 Set/Out/Nov/Dez. 2002.

HALL, Stuart. Da diáspora: identidades e mediações culturais. In: SOVIK, Liv (Org.). Representação da UNESCO no Brasil. Belo Horizonte: UFMG, 2003. 434 p. $102 \mathrm{p}$.

A identidade cultura na pós-modernidade. 11. ed. Rio de Janeiro: DP\&A, 2006.

HELLER, Agnes. O cotidiano e a história. 4 ed. São Paulo: Paz e Terra, 1992.

LEITE, Luciane Andréia, R. Era uma vez uma menina muito bonita: uma prática pedagógica relacionada com a questão racial em uma turma de alfabetização. In: Cadernos de aplicação. Porto Alegre v. 18, n. 1-2, jan/dez. 2005.

LIMA, Maria da Glória, S. B.; PEREIRA, Vanderléa, A. A pesquisa etnográfica: construções metodológicas de uma investigação. In: ENCONTRO DE PESQUISA EM EDUCAÇÃO DA UFPI, 6., 2010.Teresina. Anais... Teresina: EDUFPI, 2010, p. 1-13.

LUO, Pregador. Intérprete: Apocalipse 16. Vou colher sorrindo. In: LUO Pregador. Apresenta 7T. [S.1]: 7Taças, 2007. 1 cd sonoro. Faixa 1.

MUNANGA, Kabengele. Rediscutindo a mestiçagem no Brasil: identidade nacional versus identidade negra. Petrópolis: Vozes, 1999. 152 p.

PIRES, Gabriela. Fragmentos do descobrir-se negra. In: Blogueiras negras. Disponível em < http://blogueirasnegras.org/2014/01/14/fragmentos-descobrir-se-negra/> Acesso em 05 fev. 2014.

PROGRAMA de educação tutorial - PET - $(\mathrm{Re})$ conectando Saberes, fazeres e práticas: rumo à cidadania consciente. Universidade Federal de Uberlândia. 2010. Disponível em:

$<$ http://www.petreconectando.facip.ufu.br/> Acesso em: 18 jan. 2013. 
MC'S, Racionais. Intérprete: Racionais Mc's.Capítulo 4 Versículo 3. In: MC'S, Racionais. Sobrevivendo no inferno. [S.1: S.n.], 1998. 1 disco sonoro. Faixa 03.

SILVA, Tomaz Tadeu da. A produção social da identidade e da diferença. In: SILVA, Tomaz Tadeu (Org.) Identidade e diferença: a perspectiva dos estudos culturais. Petrópolis: Vozes, 2000. 